\title{
ESTUDOS COMPARADOS DE LITERATURAS: POSSIBILIDADES PARA O ENSINO
}

\author{
Maria Zilda da Cunha (USP) \\ Maria Auxiliadora Fontana Baseio (USP)
}

Resumo: Em face dos desafios que demanda a educação neste milênio, tendo em vista o ruir do antigo paradigma marcado pela disjunção, pela hiperespecialização, torna-se importante revisar práticas pedagógicas que envolvem a literatura. Busca-se avaliar princípios e dinâmicas cristalizados no ensino, entre os quais os da historiografia literária, que tem resultado em práticas de leitura um tanto panorâmicas, simplificadas e superficiais. Com uma visão fragmentada das obras literárias, muitas vezes para atender demandas de processos seletivos, o aluno realiza uma leitura ilustrativa de uma teoria ou de uma escola literária, em detrimento da fruição estética capaz de fazer valer questões existenciais, sociais e culturais do ser humano. Enlaçar, neste momento da história humana, literatura e educação, é redimensionar forças, é intercambiar saberes. Este artigo discute, por meio de pesquisa bibliográfica, a possibilidade de ensino de Literaturas de Língua Oficial Portuguesa a partir dos Estudos Comparados. Para tanto, perfaz-se uma análise de duas obras pertencentes ao macrossistema literário de língua portuguesa, colocando sob mira os projetos estéticos de Manoel de Barros e Mia Couto. Ambos estabelecem vínculo por meio da Língua Portuguesa, que oferece a possibilidade de irmanar as experiências. Conhecer linguagens literárias e projetos estéticos que sensibilizam para a compreensão de diferentes culturas contribui para relações mais humanitárias na medida em que faz possível analisar semelhanças e diferenças. O diálogo de autores e obras permite-nos analisar questões interculturais e intersemióticas, constituindo-se como proposta reflexiva para compreensão crítica do fenômeno literário e para o reconhecimento e valorização da diversidade e da reciprocidade.

Palavras-chave: Ensino de Literatura; Estudos Comparados; Interdisciplinaridade.

Abstract: Due to the challenges demanded by education in this millennium, because of the collapse of the old paradigm marked by disjunction, by hyperspecialization, it becomes important to review 
pedagogical practices that involve literature. It is necessary to evaluate principles and dynamics crystallized in teaching, including those of historiography, which has resulted in panoramic, simplified and superficial reading practices. With a fragmented view of literary works, often to meet demands of selective processes, the student performs an illustrative reading of a theory or a literary style, in spite of the aesthetic fruition, which values existential, social and cultural issues of the human being. Relating literature and education is important to resize forces, to exchange knowledge. This article discusses, by a bibliographic research, the possibility of teaching Literature with the methodology of Comparative Studies. Therefore, an analysis of two works belonging to the Portuguese-language literary macrosystem is carried out, placing the aesthetic projects of Manoel de Barros and Mia Couto under consideration. Both establish a relation through the Portuguese Language, which offers the possibility of joining the experiences. Knowing literary languages and aesthetic projects that sensitize the understanding of different cultures contributes to more humane relationships as well as it makes possible to investigate similarities and differences. The dialogue between authors and works allows us to analyze intercultural and intersemiotic questions, constituting as a reflexive proposal for a critical understanding of the literary phenomenon and for the recognition and appreciation of diversity and reciprocity.

Keywords: Comparative Studies; Education; Teaching; Interdisciplinarity.

\section{INTRODUÇÃO}

O estágio em que nos encontramos, permeado pelas céleres transformações nos processos de informação e comunicação, do saber e da conexão humanos, são processos mediados por formas de tecnologia nômades, por redes móveis que viabilizam aprendizagens instantâneas, assistemáticas, espontâneas e caóticas. Esses processos, agenciados por curiosidades contingentes, são efetivados pelo acesso livre à informação, via internet. Seguramente, 
são formas de aprendizagem que estão lançando desafios novos e severos à educação, afetando diretamente as formas de ensinar e aprender. São desafios que exigem a revisão das certezas que estavam subjacentes ao paradigma dos modelos a priori, por conseguinte das formulações dos currículos e das orientações de práticas escolares que por tanto tempo têm norteado ações pedagógicas ${ }^{1}$.

Se, de um lado, verificamos que passam a conviver práticas de educação à distância, possibilitadas pelas tecnologias disponíveis, e práticas presenciais, assim como convivem vários suportes como os tablets, computadores e livros, por outro, a convivência e a articulação entre os diferentes campos do saber ainda estão a demandar uma reflexão mais adequada aos desafios impostos pela contemporaneidade.

Conforme sabemos, o século $\mathrm{XX}$, referenciando os processos de especialização fechada e de fragmentação, sedimentou mecanismos de disjunção. Essa concepção disjuntiva, parcelada, compartimentada e reducionista fortalecida no século XX permanece alicerçando perspectivas

1 Observamos, no que se refere à literatura e ensino, que, ao longo do tempo, a literatura sempre se manteve distante de seus leitores no ambiente escolar, em virtude da forma como era trabalhada. Concebida como "Belas Artes", carrega a elitização. O ensino distanciado da literatura é uma característica marcante desde que foi incluída nos currículos escolares brasileiros com a reforma educacional de 1889; o objetivo será o estudo do estilo dos autores através do estudo da biografia. A partir de 1960, há algumas mudanças, mas continua presente a periodização literária. Em que pese as diferentes propostas de mudanças curriculares, que se seguem, o paradigma da fragmentação, das especialidades, a perspectiva da historiografia, e a recorrente abordagem panorâmica e classificatória permanecem. 
pedagógicas, ainda nesta Era planetária. Uma Era que reclama a compreensão da complexidade que nos engendra e que, seguramente, demanda um pensamento que visualize o contexto, o global, o multidimensional. No dizer de Edgar Morin, urge o desenvolvimento do pensamento complexo - capaz de compreender o sentido de união de diversos elementos do todo na construção de um tecido interdependente e interativo.

Conforme assinala o referido autor, se a nossa comunidade é a Terra-Mãe, importa validar as nossas relações a partir de uma consciência ética e política capaz de entrever a unidade humana fundamentada no sentimento de pertencimento a esse lugar de convivência. Educar, nessa perspectiva, pressupõe propiciar a conjunção dos homens em uma mundialização solidária, valorizando uma ética inclusiva, alicerçada na construção de uma sociedade-mundo. Enlaçar literatura e educação, neste momento da história humana, é redimensionar forças, é intercambiar saberes. Neste sentido, o trabalho com os Estudos Comparados de Literaturas de Língua Portuguesa tem-se revelado, a nós, como educadores, uma possibilidade de diálogo interdisciplinar, intercultural e intersemiótico, um campo do saber que propicia perscrutar a complexidade das relações humanas. 
Na perspectiva de Benjamin Abdala Junior (2003), esse campo do conhecimento permite estudos que ultrapassam as fronteiras nacionais, o tempo, as línguas, os gêneros, e estabelece diálogos entre literaturas, entre culturas, artes e outras áreas do saber. Nesse sentido, o comparatismo da solidariedade, tal como propõe o estudioso, constituise como um espaço reflexivo para compreensão crítica do fenômeno literário que contribui significativamente para uma circulação de repertórios culturais em que se reconhece e se valoriza a diversidade e a reciprocidade. Segundo Tânia Carvalhal (2003, p.36),

Acentua-se, então, na caracterização da disciplina, um traço de mobilidade, enquanto se preserva sua natureza mediadora, intermediária, característica de um procedimento crítico que se situa entre dois ou mais elementos, explorando seus nexos e relações. Fixase, enfim, seu caráter interdisciplinar.

Importa considerar que no seio do processo perverso de globalização como o que vivenciamos, marcado por um capitalismo neosselvagem, despontam perspectivas críticas de perceber o mundo com reconfigurações de estratégias e formas de articulações que levam em conta as esferas culturais e interculturais. Pelas margens das assimetrias econômicas, abrem-se à intelectualidade possibilidades de estabelecer 
contrapontos efetivos ao paroxismo da competitividade, que se coloca como paradigma da vida econômica, social e cultural, agindo em acordo com a lógica assimétrica dos fluxos econômicos (ABDALA, 2013). Os Estudos Comparados de Literaturas de Língua Portuguesa têm procurado efetivar enlaçamentos complexos pelas vias do comunitarismo cultural, tendo em conta que os escritores pertencentes ao macrossistema ${ }^{2}$ de língua portuguesa, por meio do estético, marcam seus discursos de matizações políticas.

Consoante ao exposto, compreendendo a importância de o jovem vivenciar níveis de leitura dos textos literários, este trabalho visa a discutir, como potente possibilidade metodológica, o ensino de Literaturas de Língua Oficial Portuguesa a partir dos Estudos Comparados. Para tanto, perfaz-se uma análise de duas obras pertencentes ao macrossistema literário de língua portuguesa, colocando sob mira os projetos estéticos ${ }^{3}$ de Manoel de Barros e Mia Couto.

\section{O PROJETO ESTÉTICO DE MANOEL DE BARROS}

Manoel de Barros, em seu projeto de escrita, evidencia sua recusa aos valores do capitalismo. Matéria de poesia para ele são "as coisas que não pretendem", "tudo aquilo

2 Essa noção de "macrossistema" foi assinalada por Benjamin Abdala Junior e enraíza-se no conceito de sistema literário proposto por Antonio Cândido.

3 Aos quais subjaz o político e ideológico. 
que nos leva a coisa nenhuma e que você não pode vender no mercado". Nesse propósito, desinventa objetos na mesma medida em que reinventa a linguagem e a língua portuguesa para plasmá-los.

Desinventar objetos. O pente, por exemplo. Dar ao pente funções de não pentear. Até que ele fique à disposição de ser uma begônia. Ou uma gravanha.

Usar algumas palavras que ainda não tenham um idioma. (BARROS, 2006, p.11)

Ao romper com o valor de uso e de troca dos objetos, faz uma literatura que cria aberturas para o novo. Para isso, busca uma língua também nova, inspirada na reinvenção das formas, sugerindo arranjos poéticos insólitos, que provocam estranhamento e surpresa no leitor.

Em sua obra, o escritor valoriza o pensar intuitivo que difere do pensar dedutivo e conceitual. É por essa abertura ao novo que ele incursiona nos terrenos do onírico, subvertendo a lógica cartesiana e desafiando-nos a rever certezas e a esperar o inesperado.

Uma rã me pedra (A rã me corrompeu para pedra. Retirou meus limites de ser humano e me ampliou para coisa. A rã se tornou o sujeito pessoal da frase e me largou no chão a criar musgos para tapete de insetos e de frades.). (BARROS, 2004, p.13) 
Como recusa ao paradigma marcado pela racionalização, Manoel de Barros instaura uma língua de brincar, orientada por uma gramática surreal, em que imagens e vocábulos revelam um olhar singular e um sentir inaugural capazes de criar fissuras na realidade instituída.

Essa experiência lúdica reúne realidades aparentemente incompatíveis apresentadas por "peraltagens" semânticas, sintáticas, sonoras, que põem a realidade conhecida, tangível e estável à revelia e mostram o ato criador e recriador que engendra a poesia. Com essa disposição da palavra de forma lúdica, impulsiona o homem reinventar a vida, o mundo e uma nova forma de estar no mundo.

Seu projeto de resistência apresenta muitas faces: recusa as degradações ambientais, a uniformização e a quantificação, a vida prosaica puramente utilitária, a primazia do consumo, a tirania do dinheiro, o pensamento único. Em contrapartida, propõe um olhar de comunhão - não de cisão - entre homem e natureza, sujeito e objeto, convidando-nos a uma outra visão de mundo.

Esse olhar de comunhão estende-se também à relação entre os homens. Seus personagens, cujos nomes são escritos conforme se pronunciam, revelam a solidariedade do poeta com todos aqueles que circulam às margens do 
poder instituído e que se expressam pela oralidade. Nesse sentido, aponta uma possível gramática social que reúne pessoas e aspirações diversas em torno de uma busca comum, na medida em que somos filhos, ao mesmo tempo de nosso chão e da Terra, compartilhamos o mesmo destino.

Ao mesmo tempo em que nos mobiliza o olhar para além do local, seus poemas também valorizam as raízes, o chão brasileiro, despertando o sentimento de pertença a esse lugar em que nascemos. Recria provérbios, adivinhas, cria personagens e formas de expressão que fazem ressoar a voz do contador de histórias, recuperando a "performance", característica da tradição oral. Mas seu intuito é ainda maior na busca de atingir a linguagem e as relações humanas e com a natureza em estado inaugural. Para isso, propõe um destecer da história, metaforizado pelo desler do livro, como sugere:

A voz de meu avô arfa. Estava com um livro debaixo dos olhos.

Vô! o livro está de cabeça pra baixo.

Estou deslendo. (BARROS, 2006, p.30)

Pela voz do avô, Manoel de Barros vai destecendo a cultura humana, decompondo liricamente a história ocidental. Nesse propósito, valoriza a infância, sua linguagem e forma de pensamento. Em sua arquitetura poética, recupera o início

4 No sentido proposto por Paul Zumthor (1993). 
dos cantos do homem, o nascedouro da linguagem, para que, refeita, possa reinventar um novo mundo. Alquimista da palavra, o poeta descarna o verbo até entrever sua estrutura seminal, operando no mais alto grau da potencialidade sonora, sintática, semântica, enfim, estética. Cruza sentidos e sensações, sua linguagem é feita com o corpo, para ser incorporada.

De primeiro as coisas só davam aspecto Não davam idéias.

A língua era incorporante. (BARROS, 2006, p.85)

Inventa, dessa forma, uma gramática afetiva e ao mesmo tempo combativa. Verbos e nomes compõem a substância primordial da linguagem do autor, com os quais ele recupera a arte primeira de nomear. A inversão do sujeito e do objeto rompe com a sintaxe acostumada, propondo novas relações e significados:

Um perfume vermelho me pensou.

(Eu contamino a luz do anoitecer?) (BARROS, 2006, p.69)

Abusa da metalinguagem - o que traduz a consciência de seu fazer poético, de forma a tornar a poesia uma crítica da linguagem. Vale-se da intertextualidade, exigindo do leitor que desbrave seu acervo imaginário, cabendo-lhe o papel de 
coautor. Deixa evidente que seu fazer poético se faz mais por encantamento e por instinto e menos por pensamento instrumentalmente racionalizado: "Não é por fazimentos cerebrais que se chega ao milagre estético senão por instinto linguístico" (BARROS, 2004, p.81). Isso não significa descartar a intencionalidade, pois é assim mesmo que ela se revela.

Sua poesia oscila entre o efêmero e o eterno, entre o lírico e o grotesco, entre a forma fixa e o experimentalismo, entre a poesia e a prosa, entre o cantar e o contar.

- Difícil entender, me dizem, é sua poesia, o

senhor concorda?

- Para entender nós temos dois caminhos: o da

sensibilidade que é o entendimento do corpo; e o da

inteligência que é o entendimento do espírito.

Eu escrevo com o corpo

Poesia não é para compreender mas para incorporar

Entender é parede: procure ser uma árvore. (BARROS, 2004, p.37)

Manoel de Barros sugere ser papel da poesia sensibilizar o humano por meio de uma língua reinventada, e o do poeta, criar um território imaginário como lugar da reinvenção capaz de impulsionar a transformação das relações humanas. 


\section{A LITERATURA DE MIA COUTO}

Como confirma em Pensatempos, Mia Couto traz em sua literatura uma profunda reflexão sobre a tradição e a modernidade. Nessa consideração, assinala traços importantes de seu projeto estético.

Deixámos de escutar as vozes que são diferentes, os silêncios que são diversos. E deixámos de escutar não porque nos rodeasse o silêncio. Ficámos surdos pelo excesso de palavras, ficámos autistas pelo excesso de informação. A natureza converteu-se em retórica, num emblema, num anúncio de televisão. Falamos dela, não a vivemos. A natureza, ela própria, tem que voltar a nascer. $(2005$, p.123)

Sabe-se que a escuta tem caráter gregário, porque pressupõe um que fala e outro que ouve. A oralidade implica condição daquilo que em nós se orienta diretamente para outrem. Falar é se oferecer ao outro; escutar é receber, acolher, abrir-se ao diferente. Os dois movimentos, falar e receber constituem duas formas de se reafirmarem os laços comunitários.

Amadou Hampâte Ba (Apud MATTOS, 2005, p.79) costumava dizer que "na África é contando histórias que se constrói a aldeia". Nesse intercâmbio, recupera-se a capacidade de dar conselhos, e o conselho, "tecido na 
substância viva da existência, tem um nome: sabedoria" (BENJAMIN, 1994, p.200). Evidente que essa sabedoria aparece, em Mia Couto, alinhavada em livro, portanto a marca artesanal da narração não se perde, é resgatada por um novo contador, capaz de recuperar o tempo em que o tempo não contava.

A reinauguração do mito, como forma da tradição, retecido no romance, como se observa recorrentemente em textos do autor moçambicano, é a alternativa escolhida para levar-nos a um pensar sensível. Seu convite faz-nos ouvir atentamente, com consciência, não só a voz da natureza, mas também a voz dos ancestrais.

Anuncia uma nova espécie de conhecimento, cuja lógica reflete a feição de sua cultura. Assim, em Pensatempos, responde às questões postas hoje:

O que podemos fazer, nos dias de hoje, é responder à globalização desumanizante com uma outra globalização, feita à nossa maneira e com os nossos próprios propósitos. Não tanto para contrapor. Mas para criar um mundo plural em que todos possam mundializar-se e ser mundializados. Sem hegemonia, sem dominação. Um mundo que escuta as vozes diversas, em que todos são, em simultâneo, centro e periferia. [...] Se os outros nos conhecerem, se escutarem a nossa voz e, sobretudo, se encontrarem nessa descoberta um motivo de prazer, só então estaremos criando esse território de 
diversidade e de particularidade. O problema parece ser o de que nós próprios - os do Terceiro Mundo - nos conhecemos mal. [...] A visão que temos da nossa História e das nossas dinâmicas não foi por nós construída. Não é nossa. Pedimos emprestado aos outros a lógica que levou à nossa própria exclusão e à mistificação de nosso mundo periférico. Temos que aprender a pensar e a sentir de acordo com uma racionalidade que seja nossa e que exprima a nossa individualidade. (COUTO, 2005, p.156)

São várias as vozes para as quais o escritor empresta sua letra: vozes de brancos, negros, animais, mortos, conhecidas e desconhecidas, com as quais atualiza seu plano estético de costurar tradição e modernidade, valorizando as identidades.

Lendas, mitos, adivinhas, provérbios, entre outras formas da tradição oral se reapresentam nas obras do autor, sendo os provérbios bastante recorrentes. Muitas vezes parodiados, como em: "preparado para o que desse e não viesse" (COUTO, 2003, p.60); "nenhuma cabeça, nenhuma sentença" (COUTO, 2004, p.11), servem de recurso para questionar verdades estabelecidas pela repetição. Em consonância com Rita Chaves (1999, p.160), "se num mundo movido pelo dinamismo das mudanças sociais, o provérbio pode ser encarado como uma expressão de conformismo, num universo calcado na imobilidade e na exclusão, a fala popular ganha tons de subversão". 
Em seu projeto de escrita, Mia Couto trabalha a língua com todos os mecanismos disponíveis para criar. Subverte a norma-padrão do português europeu, ao adotar inovações lexicais, por meio desse processo inventivo que se observa em uma quantidade significativa de neologismos.

O autor não hesita em recorrer a imprevisíveis "brincriações", como se nota em: "sou um aparente parente" (COUTO, 2003, p.30), "mais sedento que sedentário" (COUTO, 2003, p.42); entre tantas outras. É por essa atitude que Mia Couto nos devolve, sobretudo na prosa, os ritmos da própria poesia.

O escritor nos apresenta a língua portuguesa como um sistema aberto e, ao mesmo tempo, afetivo, empregando, com reconhecida singularidade, uma linguagem extremamente impressiva.

O lirismo que acompanha seus escritos em prosa tinge-a de poeticidade, pela habilidade com que faz uso de figuras de linguagem: sinestesias, comparações, metáforas tornam suas narrativas substancialmente mais afetivas, levando o leitor a trilhar os caminhos da sensibilidade.

A opção por recursos literários renovadores da dimensão afetiva favorece a aproximação dessa literatura com a criança e com o jovem. Entretanto, ao mesmo tempo em que 
trabalha com o lúdico opera com o filosófico, convidando o leitor a um duplo exercício: ao jogo estético e, ao mesmo tempo, reflexivo. Dessa maneira, Mia Couto vai concedendo ao leitor a possibilidade de viver experiências que alinhavam formas distintas de perceber a realidade e de pensá-la. É com essa intenção que afirma: "o que um escritor nos dá não são livros. O que ele nos dá, por via da escrita, é um mundo" (COUTO, 2005, p.120), um mundo que se plasma, imaginariamente, pelo sêmen de uma nova linguagem artística, engravidada por uma língua já velha, mas, que por estar em estado de festa, é capaz de renovar a letra pelo sopro da voz.

Aquilo que se constitui como matriz da cultura oral e da tradição é reconhecido como possibilidade para a afirmação e para a construção de um novo modo de estar moçambicano, de um novo homem africano - o que significa afirmar a convivência de tradição e modernidade em bases menos antagônicas.

Habitando regiões diversas e carregando suas rezas e segredos, as personagens de Mia Couto colocam em evidência a própria história de Moçambique, sua formação, as várias identidades que a compõem. Em geral, são nomes motivados por uma estória: em Um rio chamado tempo, uma casa 
chamada terra, apresenta-se tio Abstinêncio, que passara anos exilado dentro de casa, com medo da vida ou do viver. Isolado, ocupava-se em trançar lembranças até do que nunca tivera; Mariavilhosa, mãe do protagonista, teve um destino maravilhoso, morrendo extraordinariamente; Temporina, de O último vôo do flamingo, é uma mulher de corpo exuberante com feições de anciã; Junhito, de Terra Sonâmbula, tem esse nome porque nascera no dia da Independência, 25 de junho, entre vários outros, cegos, loucos, personagens à deriva, em trânsito e transgressão de ordens e fronteiras, capazes de compor a heroicidade silenciada da cultura africana. Animais, ndladis (pássaros míticos), seres animados e inanimados, que povoam o imaginário africano nas narrativas de Mia Couto são porta-vozes; Brancos, negros, crianças, velhos, homens, mulheres, pescadores, muitos que foram abandonados na sombra do esquecimento. Contracenam, no palco narrativo, também, feiticeiros, adivinhos, xipocos (fantasmas, em uma das línguas locais), xicuembos (espíritos dos antepassados), como vozes representantes da ancestralidade africana e, ao mesmo tempo, sua resistência.

Nas páginas do livro, desenham-se as iniciais das diversas identidades que Mia Couto faz questão de valorizar. Define, assim, o espaço literário como um entrelugar, um território de partilha e de fronteira, no qual confluem o rural e o urbano, 
a vida e a morte, o interdito e o permitido, a oralidade e a escrita, o tradicional e o moderno.

É com esse intuito que cultiva em letra as múltiplas vozes de sua terra. Fertilizando a escritura com as substâncias da oralidade, ele traduz o pensar, o sentir e o querer dos moçambicanos. Como ele mesmo afirma: no país, "noventa por cento existem na oralidade, moram na oralidade, pensam e amam nesse universo. Aí eu funciono muito como tradutor. Tradutor não de línguas, mas desses universos" (VIA ATLÂNTICA, 2005, p.208).

Ao traduzir esses universos, o autor inaugura uma realidade outra. Isso é possível porque sua escrita abre fendas na língua do colonizador, como forma de subverter a ordem colonial e consagrar um espaço em que os moçambicanos possam expressar sua moçambicanidade. Seus escritos literários engravidam o leitor de encantamento e de sonho. Como ele mesmo assume:

[...] o escritor não é apenas aquele que escreve. É aquele que produz pensamento, aquele que é capaz de engravidar os outros de sentimento e de encantamento. Mais do que isso, o escritor desafia os fundamentos do próprio pensamento. Ele vai mais longe do que desafiar os limites do politicamente correcto. Ele subverte os próprios critérios que definem o que é correcto, 
ele questiona os limites da razão. Os escritores moçambicanos cumprem hoje um compromisso de ordem ética: pensar este Moçambique e sonhar outro Moçambique. [...] esperamos pelo reacender do amor entre a escrita e a nação enquanto casa feita para sonhar. (COUTO, 2005, p.63)

Para o autor, o escritor tem compromisso com a liberdade. Por isso, sua literatura posiciona o leitor nesse entrelugar, entre tradição e modernidade, entre memória e possibilidades do vir-a-ser.

\section{POR UMA LEITURA COMPARADA}

Conhecer linguagens literárias e projetos estéticos que sensibilizam para a compreensão de diferentes culturas contribui, sobremaneira, para relações mais humanitárias na medida em que torna possível ponderar semelhanças e diferenças e respeitar a diversidade cultural.

Tanto Manoel de Barros quanto Mia Couto trazem à baila um acervo cultural que assemelha as culturas brasileira e moçambicana: valorizam a escuta, que coloca os seres em diálogo, que transporta o leitor às rodas de estórias ao pé do fogo, sensibilizados com a poesia do verbo. Ambos estabelecem esse vínculo por meio da Língua Portuguesa vetor da história, da memória e também do vir-a-ser - que oferece a possibilidade de irmanar as experiências. Lúdica, 
afetiva e festiva é a língua com a qual os autores sonham em instaurar uma nova ordem.

Cada um, à sua maneira e com uma escrita literária fecundada pela oralidade e grávida de elementos imagéticos, busca suas raízes culturais e seus sentimentos de pertença. Não lhes falta inventividade, nem sensibilidade, para fazer fruir o verbo e colocar a palavra em festa, possivelmente no vislumbre de uma nova comunhão dos homens.

A escolha por recriar a tradição oral é a maneira que os dois inventores da língua encontram para restaurar as formas primeiras de convivência humana. Em Manoel de Barros, a entrevisão do primordial; em Mia Couto, a escuta dos antepassados. Em ambos, a qualidade do gesto vocal, que aproxima os seres humanos no reconhecimento de corpos e na partilha de histórias e sentimentos comuns da condição humana. Ambos imprimem a magia da voz nas ranhuras da letra, introduzem fantasia na aspereza do pensar estabelecido, inscrevem afetividade na atividade racional, paixão na razão, sentido no vazio da vida banal - todos ingredientes necessários para que se inaugure o presente.

Tanto Manoel de Barros, quanto Mia Couto valorizam o chão, a Terra, fazendo questionar os efeitos de uma civilização reduzida ao dinheiro, ao prosaico, evocando uma sociedademundo, que abrigue, no mesmo lar, diferentes etnias, 
valorizando o sentimento de pertença e de enraizamento a uma Terra-pátria em que os homens possam comungar sentimentos e pensamentos. Em travessia, perambulando por espaços múltiplos, eles reinventam um entrelugar, por princípio imaginário, motivador do diálogo das culturas, projetando uma nova forma de cidadania - a transfronteiriça e intercultural - e uma nova forma de identidade - sempre em curso.

\section{CONSIDERAÇÕES FINAIS}

Em razão dos desafios que nos ocupam em revisar antigos paradigmas, com propostas de reformulação de currículos e de orientações metodológicas para o ensino da literatura, em uma Era que reclama a compreensão da complexidade, os Estudos Comparados de Literaturas de Língua Portuguesa, alimentados pela força da interdisciplinaridade, mostram-se frutíferos para a discussão de relações interculturais e intersemióticas.

Trata-se aqui de reavaliar princípios e dinâmicas cristalizados no ensino de literatura, entre os quais os da historiografia literária, que recorrentemente tem sido usada resultando em leitura panorâmica, simplificada e superficial, sustentada por uma visão fragmentada das obras literárias. Seja pelo uso de livros didáticos, seja pela forma como são abordadas em sala da aula no intuito de atender demandas de processos seletivos, 
essas obras são estudadas com concepção conteudista, levando o aluno a uma leitura ilustrativa de uma teoria ou de uma escola literária e não como um objeto estético passível de fruição, capaz de dialogar com questões existenciais, sociais, culturais do ser humano.

Propõe-se, neste artigo, um olhar para a arte literária como fenômeno cultural e de linguagem e para o texto como objeto estético na sua inteireza, como corpo significativo e dialógico, capaz de criar ressonâncias com o leitor, com o contexto social em que este se insere, com outras culturas, com outras obras, com outros tempos e outros espaços.

Como fenômeno de linguagem, a literatura transfigura a experiência humana e atua pela organização estética, pela qualidade de sentimento, pela forma como cada subjetividade interage com ela, engendrando modos de intelecção e reflexão crítica. Importa, ressalte-se, o caráter estético a despeito da escolarização.

Nessa proposta, compreende-se cada obra na sua singularidade e autonomia, bem como o diálogo de saberes e de culturas como exercício de aproximação e de distanciamento de si e do outro. O ensino da literatura a partir de uma perspectiva de diálogo intercultural e interdisciplinar demanda muitas reformulações práticas, que seriam impossíveis sem a reformulação do pensamento. 
Por fim, não podemos abandonar a compreensão de que há bens materiais, ou que atendem a necessidades físicas, como casa, alimentos, saúde, etc., assim como há bens simbólicos, como a literatura, que atendem a necessidades espirituais e sociais, que, portanto, assumem-se, conforme Candido (2011), como direitos inalienáveis, cuja falta resultaria na impossibilidade de confirmar no homem sua própria humanidade.

\section{REFERÊNCIAS}

ABDALA JR., Benjamin (2003). De vôos e ilhas: literaturas e comunitarismos. São Paulo: Ateliê Editorial.

(2002). Fronteiras múltiplas, identidades plurais. São Paulo:

Senac.

BARROS, Manoel. (2006). Livro sobre o nada. 12.ed., Rio de Janeiro: Record.

(2008). Memórias inventadas: a terceira infância. São Paulo: Planeta.

(2005). Tratado geral das grandezas do ínfimo. 3.ed. Rio de Janeiro: Record.

(2006). O guardador de águas. 5.ed. Rio de Janeiro: Record. (2001). O fazedor de amanhecer. Rio de Janeiro, Salamandra.

BASEIO, Maria Auxiliadora Fontana (2007). Entre a magia da voz e a artesania da letra: o sagrado em Manoel de Barros e Mia Couto. Tese (Doutorado em Letras) - FFLCH, Universidade de São Paulo, São Paulo.

BENJAMIN, Walter (1994). Magia e técnica, arte e política: ensaios sobre literatura e história da cultura. Sérgio Paulo Rouanet (Trad.). 7.ed. São Paulo, Brasiliense.

BOSI, Alfredo (2000). O ser e o tempo da poesia. 6.ed. São Paulo: Companhia das Letras. 
CANDIDO, Antonio (1997). Formação da literatura brasileira. 8.ed. v.1. Belo Horizonte: Itatiaia. (2006). Literatura e sociedade. 9.ed. Rio de Janeiro: Ouro sobre Azul. (2011). Vários Escritos. Rio de Janeiro: Ouro sobre Azul.

CAVACAS, Fernanda (2001). Mia Couto: acrediteísmos. Lisboa: Mar Além, Edição de Publicações.

CARVALHAL, Tania Maria Franco (2003). O próprio e o alheio. São Leopoldo: Editora da UNISINOS.

CHAVES, Rita (2005). Angola e Moçambique: experiência colonial e territórios literários. São Paulo: Ateliê Editorial.

COUTO, Mia (2004). A chuva pasmada. Lisboa: Editorial Caminho. (2003). A varanda do frangipani. 7.ed. Lisboa: Editorial Caminho. (2000). Mar me quer. II. João Nasi Pereira. 5.ed. Lisboa: Editorial Caminho.

(2005). Pensatempos: textos de opinião. 2.ed. Lisboa: Editorial Caminho. (2004). Terra sonâmbula. 8.ed. Lisboa: Editorial Caminho. (1997). Vozes anoitecidas. 8.ed. Lisboa: Editorial Caminho. (2003). Um rio chamado tempo, uma casa chamada terra. São Paulo: Companhia das Letras.

LEITE, Ana Mafalda (2004). Literaturas africanas e formulações póscoloniais. 2.ed. Maputo, Imprensa Universitária: Universidade Eduardo Mondlane.

MATOS, Gislayne Avelar (2005). A palavra do contador de histórias: sua dimensão educativa na contemporaneidade. São Paulo: Martins Fontes. MORIN, Edgar (2003). Educar na era planetária: o pensamento complexo como método de aprendizagem no erro e na incerteza humana. São Paulo: Cortez.

PADILHA, Laura Cavalcanti (1995). Entre voz e letra: o lugar da ancestralidade na ficção angolana do século XX. Rio de Janeiro: EDUFF. 
REVISTA VIA ATLÂNTICA (1999). n.3. São Paulo, Departamento de Letras Clássicas e Vernáculas, Faculdade de Filosofia, Letras e Ciências Humanas, Universidade de São Paulo.

REVISTA VIA ATLÂNTICA (2005). n.8. São Paulo, Departamento de Letras Clássicas e Vernáculas, Faculdade de Filosofia, Letras e Ciências Humanas, Universidade de São Paulo.

ZUMTHOR, Paul (1993). A letra e a voz: a "literatura" medieval. Amálio Pinheiro e Jerusa Pires Ferreira (Trad.). São Paulo: Companhia das Letras.

Maria Zilda da Cunha é Doutora em Letras - Estudos Comparados de Literaturas de Língua Portuguesa (USP-2002); Mestre em Comunicação e Semiótica pela PUC/SP (1997); docente no programa (de graduação e pósgraduação) de Estudos Comparados de Literaturas de Língua Portuguesa e coordenadora da área de Literatura Infantil e Juvenil (USP). É líder do Grupo de Pesquisa Produções Literárias e Culturais para crianças e jovens (USP/CNPQ). Autora do livro Na Tessitura dos Signos Contemporâneos. Editora Paulinas, 2009. E-mail: mariazildacunha@hotmail.com.

Maria Auxiliadora Fontana Baseio é Doutora em Estudos Comparados de Literaturas de Língua Portuguesa (USP-2007); Mestre em Estudos Comparados de Literaturas de Língua Portuguesa (USP-2000); Professora do Mestrado Interdisciplinar em Ciências Humanas na Universidade Santo Amaro (UNISA); Lidera grupo de pesquisa Arte Cultura e Imaginário (Unisa) e pesquisadora do grupo Produções Literárias e culturais para crianças e jovens (USP). E-mail: mbaseio@uol.com.br. 